\title{
Entre la madurez y el autocontrol: una cartografía para el abordaje de la delincuencia juvenil ${ }^{*}$
}

\author{
Luis Alejandro Romero Miranda**
}

"La pericia psiquiátrica permite pasar del acto a la conducta, del delito a la manera de ser y poner de relieve que esta última no es otra cosa que el delito mismo, pero en cierto modo, en estado de generalidad en la conducta de un individuo". M. Foucault.

\section{Resumen}

En el presente texto se exponen los principales postulados de la teoría del autocontrol, así como de las teorías de la madurez intelectual y psicosocial que dan explicación al fenómeno de la delincuencia juvenil. La idea subyacente es la de contrastar los supuestos de ambas teorías a fin de determinar su pertinencia y promover la discusión en torno a sus reales alcances a la hora de abordar el fenómeno.

\section{Palabras clave}

Autocontrol, bajo autocontrol, socialización, madurez intelectual, madurez psicosocial, delincuencia juvenil, factores de riesgo generacionales.

\footnotetext{
* El presente escrito se desprende de la tesis conducente al grado de Máster en Criminología y Delincuencia Juvenil en la Universidad de Castilla-La Mancha, España denominada Análisis de la Conducta de Microtráfico de Drogas en Niñas y Adolescentes desde la Perspectiva General del Delito.

** Sociólogo U de C, Chile. Máster en Criminología y Delincuencia Juvenil de la Universidad de Castilla-La Mancha, España.
} 


\title{
Between Maturity and Self-control: a Map for Addressing Juvenile Delinquency
}

\begin{abstract}
In this article the main tenets of the theory of self-control are discussed, as well as theories of intellectual and psychological maturity to give an explanation to the phenomenon of juvenile delinquency. The underlying idea is to contrast the assumptions of both theories to determine their relevance and promote discussion around their real scope to tackling the phenomenon.

\section{Keywords}

Self-control, low self-control, socialization, intellectual maturity, psychosocial maturity, juvenile delinquency, risk factors generational.
\end{abstract}




\section{La teoría del autocontrol}

Si hemos de buscar los principios que se encuentran en la base de la teoría del autocontrol, es necesario hacer alusión a la teoría del control social, en especial, al supuesto que señala que las personas tienen una cierta tendencia natural a delinquir, hecho que se producirá si no existen razones o motivos que lo impidan (Serrano, 2009). Por lo tanto, la pregunta esencial de la teoría del control siguiendo a Hirschi- no es ¿por qué los sujetos delinquen?, sino justamente ¿por qué no lo hacen?

Es en el contexto de este interrogante, donde la teoría del autocontrol encuentra un terreno fértil para germinar, al proponer que la causa principal de la conducta pro social o no delictiva en los sujetos (por ende, la causa principal para refrenar la tendencia natural a delinquir y a la desviación) se encuentra en las propias habilidades y barreras que los sujetos desarrollan y que tienen su origen en la socialización, es decir, en el proceso mediante el cual los individuos comienzan paulatinamente a interiorizar y aceptar las normas y límites que guían y establecen la convivencia social. De esta manera, la socialización se transforma en la piedra angular del autocontrol (self-control), que es definido por Gottfredson y Hirschi (1994) "como el rasgo individual que explica las variaciones en la probabilidad de ser atraídos por actos (delictivos) en los que el autor ignora las consecuencias negativas a largo plazo" (p. 2).

Así, la diferencia fundamental entre la teoría general del delito (autocontrol) y la teoría del control de 1969, radica en que, para la primera de estas, el delito es producto intrínseco del bajo autocontrol y no obedece necesariamente a una vinculación con entornos o personas convencionales como sí lo plantea la segunda (Rodríguez, 2010).

Estos principios, y otros que dan forma al autocontrol como teoría, se inician con la publicación de The General Theory of Crime de Michael Gottfredson y Travis Hirschi (1990). En este libro, los autores plantean que el principal elemento para cautelar y evitar conductas antisociales y delictivas es el self-control, que se forma a una edad muy temprana en los sujetos y se mantiene relativamente estable e indestructible a partir de ese momento, de manera que, a los ocho o diez años, la mayoría de los individuos ya ha aprendido a controlar su tendencia natural hacia la desviación, aún cuando factores externos favorezcan la oportunidad de delinquir. Como señala Juan Rodríguez: 
Para Hirsch, el ser humano por naturaleza presenta una propensión hacia la desviación, siendo los diferentes vínculos con la sociedad los elementos que inhiben esta disposición. De tal manera que el apego, las creencias, el compromiso y la participación fungen como lazos necesarios para mantener una conexión con los entornos convencionales (familia, escuela y amigos) y por lo tanto para impedir la conducta antisocial (2010, p. 217).

De esta suerte, y como noción central de su teoría, Gottfredson y Hirschi ponen al autocontrol como producto directo de la socialización familiar (o socialización primaria), donde la labor desarrollada por los padres juega un papel gravitante como mecanismo destinado a la educación pro social (que favorece o permite la vida en sociedad, por consiguiente, en concordancia con los valores consensuados a nivel estructural) y la corrección de conductas antisociales (que atentan contra la convivencia social); de esta forma, aumentando y potenciando el autocontrol de los niños se evitaran futuros comportamientos delictivos (Gottfredson \& Hirschi, 1990; Vásquez, 2009). Como apunta Alfonso Serrano:

Una socialización correcta del niño o la niña se caracteriza, según Gottfredson y Hirsch, por un seguimiento de su comportamiento, lo cual faltará cuando los padres no se preocupen por ellos, no tengan tiempo ni energías para ello, o simplemente cuando no sientan cariño (hacia el niño), o cuando falle el reconocimiento del comportamiento desviado cuando éste se produce, o bien cuando el comportamiento desviado no se reprime (2009, p. 11).

De esta manera, siguiendo la secuencia descrita en las líneas antecedentes, la conducta delictual tiene su origen y explicación en el bajo autocontrol de los sujetos para refrenar sus impulsos desviados, bajo control que surge como resultado del deficiente trabajo de los padres en la socialización del niño o falta de técnicas parentales de educación (Ratchford \& Beaver, 2009), caracterizada por la ausencia de disciplina y la falta de imposición de reglas al interior de la familia. En términos concretos, el bajo autocontrol sería resultado de: a) la falta de vigilancia y supervisión del comportamiento del niño, b) la incapacidad o falta de crítica de los padres para detectar y reconocer conductas desviadas o antisociales en el hijo y c) la permisividad frente al acto antisocial, que se traduce en la falta de castigo frente al propio acto a fin de ser reprimido.

Finalmente, Gottfredson y Hirschi plantean que los síntomas de un bajo nivel de autocontrol son ya perceptibles durante la infancia 
y se caracterizan por la incapacidad para postergar gratificaciones, la baja tolerancia a la frustración y la tendencia a realizar conductas de riesgo.

\section{Fundamentos de la Teoría General del Delito.}

Gottfredson y Hirschi establecen una diferencia entre el delito como 'acto' y la desviación como 'tendencia' (Rodríguez, 2009). La desviación la asumen como tendencia, pues, según sus postulados, esta es parte de la naturaleza misma del sujeto, razón por la cual los individuos en determinados pasajes de su vida pueden manifestarse proclives a ella (hecho que le instituye la normalidad). Por su lado, el delito es un acto, porque hace referencia a la materialización de la desviación natural como producto del bajo autocontrol de los sujetos (materialización que determina su anormalidad).

Así, para estos autores el delito es un acto de fuerza o fraude realizado en la búsqueda (y en razón) del propio interés, que supone por cuentas actos desviados, que se caracterizan por su riesgo, la recompensa inmediata que persiguen, su fácil realización y su corta duración (Serrano, 2009). De aquí que, para Gottfredson y Hirschi, los delincuentes posean características bien definidas, como su orientación a las gratificaciones inmediatas, su impulsividad y su predilección por el riesgo y la búsqueda de emociones, así como su versatilidad (no cometen siempre el mismo delito incurriendo por cuentas en otros comportamientos delictuales) y la visibilización de su carrera delictiva a muy temprana edad (todo delincuente adulto fue antes un delincuente juvenil)

\section{Correlación entre edad y delito.}

Existen tres elementos que alejan a la teoría del autocontrol de las teorías criminológicas clásicas (Serrano, 2009; Vásquez 2009). El primer punto, dice relación con la correlación que establece la teoría general entre edad y delito que da como resultado la conocida curva de edad.

Al respecto, la teoría del autocontrol plantea que la mayor parte de los delitos son perpetrados por sujetos jóvenes, en especial, por aquellos cuyas edades van entre los 15 y los 20 años; esto genera una curva estadística (campana de Gauss), que muestra como el comportamiento delictual de los sujetos se incrementa en la medida que estos se acercan a la adolescencia, y disminuye cuando entran 
a la adultez. Gottfredson y Hirschi (1990) plantean que este hecho no posee explicaciones causales, por lo cual, esta curva de edad no puede explicarse de otra forma, a no ser por la presencia de un bajo autocontrol relativamente estable en la edad adolescente. En resumen: la curva de edad demuestra como la mayor parte de los delitos son cometidos por delincuentes jóvenes, que llegan a tal resultado debido a la deficiente socialización desarrollada por sus padres.

\section{Versatilidad de los delincuentes.}

Según este idea, los delincuentes no se especializan en la comisión de delitos específicos, sino que, por el contrario, se ven envueltos en infracciones muy diversas. De aquí que, para esta teoría, no tenga sentido buscar las causas de tipos delictivos concretos, debido a que todos los delitos presentan más elementos que los unen que aquellos que los diferencian. En otros términos, los delincuentes no se especializan en delitos concretos, sino que, más bien, tienden a verse envueltos en una gran variedad de ellos según las circunstancias, razón por la cual carece de sentido buscar una explicación al delito puntual (de turno).

\section{Continuidad delictiva.}

La continuidad delictiva establece un nexo directo entre la delincuencia juvenil y la delincuencia adulta, proponiendo (y asumiendo) que todo delincuente adulto lo fue en su juventud. En otros términos, como propone Farrington (1986), "para ser delincuente adulto uno ha debido ser antes un delincuente juvenil". Por último, como señala Serrano (2009), el hallazgo de la continuidad apunta a que las causas del delito deben presentarse de manera prematura en los sujetos (infancia), ya que el comportamiento delictual difícilmente puede aparecer de forma espontánea en la adultez. Será esta noción de continuidad la que actuará como base de posteriores teorías como la teoría integradora de Farrington, el modelo de múltiples trayectorias de Loeber y el modelo de desarrollo social de Catalana y Hawkins (Vásquez, 2009).

\section{La teoría de la madurez}

Si la teoría general del delito pone a la socialización familiar como el gran elemento que sustenta el autocontrol, la teoría de la madurez, por su parte, pone acento en aspectos cognitivos para la 
correcta toma de decisiones que se patentan a través de los conceptos de inmadurez moral (Pueyo, 2008), madurez intelectual (Steinberg et al, 2009) y madurez psicosocial (Bryan-Hancock y Casey, 2010; Ratchford y Beaver, 2009).

\section{Inmadurez moral.}

Este primer término aparece ligado a la secuencia histórica que explica el comportamiento delictual juvenil y tiene su mayor auge entre mediados del siglo XIX y 1920. Se desprende de la concepción moralista de explicar la delincuencia, para la cual el centro de la criminalidad es la constitución anómala o desviada del sujeto desde su misma gestación (congénita), por lo tanto, se basa en una predisposición genética de los sujetos a la consumación de actos delictivos, si éstos no son refrenados por medio de una fuerte educación moral (Pueyo, 2008, p. 58). Esta concepción de maldad congénita aparece, entonces, como causa directa de factores biológicos de los sujetos (como una esencia), que los sitúa como individuos enfermos a quienes las medidas de corrección moral los transformarán en sujetos normales.

Como se observa, el concepto de inmadurez moral no sólo se asocia a factores intelectuales, sino que abarca la constitución completa del sujeto. Es decir, siguiendo los postulados de Goffman (1996), el concepto de inmadurez moral se relaciona directamente con la categoría de desacreditado, esto es, el propio sujeto como centro del problema; por ello, la educación moral (depositada en la Iglesia e instituciones de caridad) no esta destinada a potenciar (dado que el niño desacreditado desde su concepción ya se presenta anómalo), sino a instalar, a reformar, a esos millares de niños pobres y vagabundos que se vislumbran como el árbol torcido que se ha de enderezar.

\section{Madurez intelectual.}

Para analizar el concepto de madurez intelectual nos valdremos de los casos Hodgson (1996) y Roper (2005), ocurridos en los EE.UU., en los cuales la Asociación Americana de Psicología (APA) estableció diferentes criterios (o argumentos contradictorios) para entender la madurez de los adolescentes (hecho que hasta el día de hoy es conocido como el 'flip flop' de la APA).

En el caso Hodgson, la APA había argumentado frente al Tribunal Supremo que, debido a que los adolescentes poseen habilidades 
similares a los adultos en la toma de decisiones (ya a los catorce años), no habría ninguna razón para exigir a los adolescentes notificar a sus padres al momento de realizar un aborto. Por su parte, en el caso Roper, la misma APA propone que los adolescentes de dieciséis años son inmaduros en la toma de decisiones que los llevan a cometer crímenes, razón por la cual no pueden ser condenados a muerte (pena que se fija, entonces, a los 18 años).

Steinberg et al (2009), señalan que es fácil ver por qué muchos criticaron el proceder de la APA, dado que su postura en el caso Roper era totalmente contraria al caso Hodgson. Sin embargo, dichos autores plantean un argumento conciliador que busca establecer un orden frente a la confusión. Según ellos, la postura de la APA debe ser entendida a la luz de una clara diferencia: la forma en cómo los adolescentes toman las decisiones en uno y otro caso. Frente a un aborto, un adolescente tiene tiempo para deliberar antes de tomar una decisión final y puede, además, consultar a un experto, mientras que las circunstancias que llevan a un adolescente a cometer un crimen se caracterizan por su alta cuota de emocionalidad, la influencia del tiempo y la presión de pares.

Con esto, Steinberg et al (2009) proponen entonces que la decisión de abortar tomada por los adolescentes es más reflexiva (de aquí que no sea necesario consultar a los padres), mientras que su decisión de cometer un crimen es más impulsiva (de aquí que no se pueda aplicar la pena capital). A partir de esta tesis, se desarrolla el estudio de la capacidad juvenil de McArthur, quien demuestra como, a los 16 años, las habilidades cognitivas generales de los adolescentes son esencialmente idénticas a las de los adultos, pero su funcionamiento psicosocial es menor.

Con esto, la toma de decisiones se subdivide en dos categorías: la madurez intelectual y la madurez psicosocial, donde la propia maduración de los sistemas cerebrales responsables del razonamiento lógico sitúan a la primera como condición necesaria para el surgimiento de la segunda, dado que el desarrollo de funciones avanzadas relacionadas con la ejecución y coordinación de efectos (problemas sociales), requiere la condición previa de la madurez cerebral para su abordaje (de aquí entonces que la madurez intelectual según esta teoría sea requisito para la madurez psicosocial).

De esta forma, cuando se trate de decisiones que permitan una mayor deliberación, donde la influencia emocional y social en el 
juicio se reducen al mínimo, y donde los adolescentes puedan consultar a expertos para orientar sus dudas, estos tomarán decisiones maduras. En contraposición, frente a situaciones de impulsividad que involucren altos niveles de excitación emocional y no den cabida a la consejería especializada, es probable que la decisión del adolescente sea menos madura que la del adulto. Así, las posturas tomadas por la APA en los casos Hodgson y Roper dejan de ser contradictorias, ya que cada una de ellas hace hincapié en diferentes aspectos de la madurez (intelectual en el caso Hodgson y psicosocial en el caso Roper).

\section{Madurez psicosocial.}

Bryan y Casey (2010) plantean que, aún cuando la edad puede ser una forma adecuada de cuantificar el desarrollo formativo (como lo propone el autocontrol y la madurez intelectual), esta no tiene en cuenta la fluidez misma del hecho, lo cual implica que la edad no siempre refleja el desarrollo de ciertos aspectos de la maduración, básicamente, porque este proceso no se produce de forma simultánea y homóloga en todos los adolescentes. De aquí, entonces, que no todos los jóvenes tomen decisiones amparadas en el umbral de la madurez intelectual, sino que muchos de ellos lo hacen en base a habilidades que se desarrollan producto de la interacción con otros sujetos (madurez psicosocial).

Así, la madurez psicosocial es definida por estas autoras como el desarrollo de competencias sociales y emocionales que permiten a los sujetos dar respuestas coherentes y funcionales a problemas concretos. La ejecución de respuestas coherentes entonces (maduras), ya no es el resultado directo del desarrollo cerebral (madurez intelectual), sino que opera bajo la lógica del bien común que se sustenta en tres elementos: a) la responsabilidad, b) la perspectiva o empatía (es decir la capacidad de ponerse en el lugar del otro y ver los hechos más allá de una postura personalista) y c) la templanza del joven que se plantea como la capacidad de refrenar la impulsividad.

\section{Discusión}

Iniciaremos la siguiente discusión reflexionando en torno a los postulados de la teoría general del delito. Como pudimos observar, la teoría del autocontrol de Gottfredson y Hirschi sitúa 
a la socialización como el elemento esencial en el fortalecimiento o instalación del autocontrol y, de forma más precisa, ponen a la socialización primaria o familiar como el gran artífice del comportamiento pro social de los niños, con lo cual, la totalidad de la responsabilidad recae en los padres, quienes deben supervisar y castigar las conductas que se presenten como antisociales.

En este sentido, una primera reflexión apunta al determinismo que los autores ponen en la socialización primaria, no considerando otros agentes (aparte de la familia) que interfieren en el proceso como grupos de pares y amigos. Esto es de consideración, pues, en la medida que la escolarización va aumentando, los niños cada vez se incorporan a menor edad a la educación formal, hecho que trae como consecuencia la reducción del núcleo familiar como único elemento socializador. Es más, Gottfredson y Hirschi proponen que el niño a los 10 años ya debería tener el autocontrol formado, pero no consideran que a esa altura el menor ya ha pasado en promedio cinco años en la escuela, con lo cual, su autocontrol puede ser fortalecido o debilitado por estas nuevas interacciones a nivel de pares o generacionales.

En la misma línea, los cambios en las políticas de empleo que permiten el trabajo de ambos padres han contribuido a que muchas de las reglas familiares (incluso la supervisión y la corrección de conductas) sean delegadas en familiares cercanos (abuelas, tíos) o terceros (cuidadoras, asesoras de hogar), lo que determina que la socialización familiar se relativiza, pues, muchas veces, los hijos no adquieren los mismos valores y preceptos de sus padres, sino más bien, de quienes los cuidan. Otro elemento que merece consideración en este punto, es que, hoy por hoy, gracias a la teoría de sistemas, entendemos que la familia como tal (microsistema), se encuentra inserta en una red más amplia de interacciones y traspaso de información con otras estructuras (mesosistema, exosistema y macrosistema), donde los límites de socialización entre cada subsistema se difuminan o tornan caliginosos, imposibilitando asignar a un solo elemento (subsistema) la responsabilidad total del fenómeno.

Una segunda consideración apunta a la calidad intrínseca que los autores le asignan a la familia como factor protector $\mathrm{o}$, si se quiere, como subsistema pro social. Una vez analizada la teoría general, llama la atención que Gottfredson y Hirschi en todo momento sitúan a la familia como una unidad compensada, funcional, carente de problemas $y$, por cuentas, apta para forjar el autocontrol, pero 
la realidad nos muestra una cara diferente, cual es, que muchas familias presentan tantas disfuncionalidades que en esencia actúan como verdaderos factores de riesgo para el niño (familias iatrogénicas); esta realidad no parece ser percibida por los autores, quienes dan por sentado que la familia, en tanto unidad, siempre ha de ser funcional al autocontrol. Esto podría explicar por qué, en toda su obra, Gottfredson y Hirschi solo destinan palabras para potenciar la supervisión y la represión por parte de los padres, pero no entregan insumos para fortalecer las habilidades parentales que fortalezcan los lazos familiares.

Un tercer elemento de interés es la profunda mirada adultocéntrica que los autores tienen del autocontrol (construida a partir de la propia visión de adulto sin considerar variables generacionales). En este sentido, pareciese que el niño durante todo el proceso de socialización familiar se presenta pasivo, totalmente receptivo a la información y los preceptos que se le inculcan, no mostrando la habilidad de cuestionar, interpretar y seleccionar. En síntesis, la socialización familiar de Gottfredson y Hirschi se basa en el esquema clásico de información, donde un emisor (padres) envía un mensaje (norma, sanción, castigo) a un receptor (hijo) quien lo decodifica y entiende de forma lineal, esto es, tal como el emisor pretende. De esta forma, estos autores suponen la existencia de una realidad unívoca para los sujetos, (igual para adultos y niños), donde las miradas generacionales de entender los fenómenos carecen de importancia.

Un cuarto elemento dice relación con estas miradas generacionales ya mencionadas, que podríamos definir como factores que nacen como producto de las propias visiones y reinterpretaciones que niños y adolescentes realizan de los valores y preceptos que los adultos asumen como fundacionales de una sociedad equilibrada y normal, y que guían, por lo tanto, las relaciones familiares. En este sentido, Williams et al (2007) son certeros al plantear que en la comprensión de la violencia y delincuencia juvenil un importante factor de riesgo es el propio desconocimiento que los adultos tienen de los mundos juveniles que, junto a la cotidianización de la violencia en los medios de comunicación y en la entretención (video juegos), generan condiciones que bajarían el umbral de crítica.

Como quinto elemento aparece nuevamente el determinismo del autocontrol que no considera en su génesis otros elementos como los factores biológicos y genéticos. Al respecto, Ratchford y Beaver (2009) proponen que el autocontrol no solo sería producto 
de factores sociales, sino también biológicos, dentro de las cuales, identifican tres variables que pueden afectar los niveles de autocontrol de los sujetos: a) que el autocontrol se relaciona directamente con el funcionamiento neuropsicológico, ya que es una propiedad de la corteza prefrontal del cerebro, b) que se ve influenciado por posibles complicaciones en el parto del niño que producen déficit neuropsicológicos, y c) que existe una relación entre bajo peso al nacer y autocontrol que se traduce en déficit de atención e hiperactividad.

En la misma línea, Farrington (2005) señala que la delincuencia juvenil puede ser abarcada y comprendida a partir de una multiplicidad de factores (no solo sociales), muchos de los cuales se presentan como predictores (herencia del autocontrol). Así, para este autor, el temperamento y la personalidad del niño, su impulsividad que se transforma en uno de los predictores más certeros (citando a Lipsey y Derzon, 1998), el bajo coeficiente intelectual y escolaridad (citando a Moffitt, 1993), las pautas de crianza del niño y presencia de abuso infantil (entre las que se cuentan una pobre supervisión de conductas y hasta actitudes de padres crueles o permisivas), los conflictos entre los padres o de familia (como separaciones, divorcio, violencia intrafamiliar, hogares monoparentales), las conductas delictivas o antisociales de los padres (así como consumo de drogas por parte de estos), las familias numerosas donde la supervisión sobre los hijos se dificulta y las conductas antisociales de hermanos mayores sirven de modelo (citando a Fischer, 1994), las familias que poseen problemas socioeconómicos que validan las conductas antisociales como mecanismo de supervivencia y la presencia de amigos delincuentes que fomentan la normalización de las conductas delictivas (Reiss y Farrington, 1991), son profundos elementos que predicen el comportamiento delictual de los jóvenes y que trascienden la explicación de la socialización primaria.

Un sexto elemento es la imposibilidad de explicar la curva de edad, a no ser por un bajo autocontrol; este es otro elemento que debe ser sometido a análisis, pues resulta paradójico que mientras las formas de vivir y experimentar la niñez y adolescencia se vean influenciadas por el momento histórico y los cambios sociales de cada época, la conducta delictual de estos responda a una misma causa: la socialización familiar. Es decir, cambian los niños, los adolescentes, los padres y la familia, pero la causa sigue siendo la misma. 
Finalmente, la continuidad delictiva propuesta por Gottfredson y Hirschi se presenta como un determinismo que se torna estigmatizante. Al plantear que todo delincuente adolescente es un futuro delincuente adulto (o bien, que todo delincuente adulto lo fue en su juventud) se niega la posibilidad de cambio en las trayectorias de vida de los sujetos, pues se sitúa a la delincuencia como una pulsión latente de por vida. Esta noción, al igual que las de Wilson y Hermstein (para quienes la delincuencia se debe a diferencias individuales basadas en la impulsividad, una baja conciencia y otros condicionantes temperamentales), apunta, entonces, a esclarecer que el criminal en potencia se presenta (o vislumbra) ya en los primeros años de vida de los sujetos y se mantiene estable (constante) a lo largo de su ciclo de vida.

En contraposición a esta idea, Serrano (2003) plantea que los factores relevantes para la criminalidad varían según la edad, dando paso a tres tipos a) la 'activación', período donde la carrera delictual puede acelerarse, estabilizarse o diversificarse, b) la 'agravación', lapso que supone un aumento considerable en la actividad delictiva del sujeto, y c) la 'desistencia', donde se evidencia una desaceleración, especialización, descenso o término de la carrera delictual. En la misa línea, y contradiciendo de forma frontal al autocontrol, Moffitt, citado por Serrano (2009), plantea que la figura del antisocial debe ser entendida a partir de una doble división: a) el delincuente, sujeto cuya actividad delictiva se limita a su adolescencia y b) el delincuente persistente, quien delinque durante toda su vida. Finalmente, Blonigen (2010), apuntando en la misma dirección que Serrano, señala que los rasgos predictores de la delincuencia no pueden ser estáticos (como sí lo plantea el autocontrol), sino que, por el contrario, es necesario determinar qué rasgos de la personalidad de los jóvenes son construcciones dinámicas y cómo estos influyen el comportamiento antisocial durante toda su vida. Es este hecho, lo que sirve de base al concepto de 'medida de nivel de cambio propuesto' por el autor, que hace referencia a las variaciones que se producen en algún atributo o comportamiento del sujeto al interior de su grupo de referencia o pertenencia a través del tiempo.

En contrapunto, e iniciando la discusión de la teoría de la madurez, es necesario comenzar reconociendo su doble naturaleza, a saber: la madurez intelectual, producto de la madurez cerebral y la madurez psicosocial, que surge como resultado del desarrollo de competencias sociales y emocionales. En relación a la madurez 
intelectual, esta se alcanza como producto de la maduración de los sistemas cerebrales responsables del razonamiento lógico y la información básica, entre los que se cuentan el lóbulo frontal, parte del cerebro donde se realizan las funciones evaluativas (morales) y la toma de decisiones, que alcanza su punto de madurez tras la poda sináptica pasado los dieciocho años.

La APA (a partir de los casos Hodgson y Roper) propone que este tipo de madurez antecede a la psicosocial, por cuanto es imposible que el sujeto pueda evaluar acciones complejas (como las relaciones sociales), si antes no tiende desarrollada esta función cerebral y no cuenta, además, con apoyo para encausar sus reflexiones (como es el caso del aborto). Ahora bien, este supuesto desarrollo primario de la madurez intelectual por sobre la psicosocial, no es compartido por Bryan y Casey (2010), para quienes los adolescentes muchas veces toman decisiones en razón de las habilidades que desarrollan producto de la interacción con otros sujetos (madurez psicosocial). Es decir, que su conducta prosocial no se relaciona directamente con la evaluación intelectual de cada acción, sino, más bien, con una evaluación que se sustenta en la búsqueda del bien común (tanto para el sujeto como para los demás). Este hecho es de gran importancia, pues plantea que la madurez psicosocial surge de forma independiente de la intelectual o, en otros términos, que no es producto directo de ella.

Así, la madurez psicosocial se aleja de la intelectual, pues extiende un lazo comunicante con la responsabilidad, la empatía y la emocionalidad, elementos que ahora actúan como criterios para la toma de decisiones. Es, en este sentido, que el concepto de madurez psicosocial de Bryan y Casey se enlaza con la ética de la emocionalidad de Maturana (1997), para quien la ética (en tanto capacidad de reflexión entre el bien y el mal) se relaciona directamente con la emoción, con el amor, con la aceptación mutua y con la empatía, y no precisamente con la razón. Según Maturana, son las emociones las que guían nuestras acciones, aun cuando tratemos por todos lados de convencernos que estas son resultado de un proceso racional. El mismo expone: "nosotros usualmente no vemos el fundamento emocional de nuestra conducta ética, porque devaluamos las emociones y pretendemos que nuestras acciones deberían tener solo un fundamento racional" (Maturana, 1997, p. 101). De esta forma, un comentario final apunta a esclarecer que, al parecer, la madurez intelectual no necesariamente antecede a la 
psicosocial, sino que más bien, ambas tienen sus propios mecanismos que, si bien las tornan independientes, del mismo modo las vuelven complementarias.

Un segundo elemento para la discusión de esta teoría se relaciona con la dependencia que establece la madurez intelectual con el juicio adulto. En otros términos, cómo se establece que la consejería u orientación por parte de un adulto (o experto) influye directamente en la toma de decisiones maduras en los adolescentes. La pregunta que aquí cabe formular es la siguiente: ¿esta consejería se torna funcional porque hace reflexionar al adolescente respecto de su situación o, simplemente, porque logra convencerlo de optar por una alternativa en particular? En otros términos, ¿la toma de decisiones maduras por parte de los adolescentes dicen relación con sus propias reflexiones o, más bien, con la imposición del juicio adultocéntrico del consejo?

Estas reflexiones cobran relevancia si recordamos que, para Steinberg et al (2009), la posibilidad de contar con ayuda profesional es vital para el juicio maduro, que se debilita si esta misma consejería es realizada por amigos o grupo de pares. Es decir, pareciese que entre todos los elementos que determinan un comportamiento maduro, la aceptación del discurso adultocéntrico por parte del adolescente (discurso del experto), actúa como el criterio de mayor relevancia. Con esto, la madurez se relaciona de forma directa con la aceptación del consejo, de la orientación, en una palabra, con la transmutación del adolescente en adulto, de forma tal, que quien sopesa y escoge las soluciones frente al problema ya no es el adolescente a partir de sus propios recursos, sino el joven que se para de cara a la realidad desde los zapatos del adulto. Así, bajo esta idea, la conducta madura del adolescente es aquella que lo acerca al juicio adulto.

Un tercer elemento dice relación con la poca valoración que la madurez intelectual asigna a las representaciones sociales que los adolescentes tienen de los fenómenos que, en muchos casos, influyen de manera directa la toma de sus decisiones. Como señala Moscovici:

La representación social es un sistema de valores, de nociones y de prácticas relativas a objetos, aspectos o dimensiones del medio social, que permite, no solamente la estabilización del marco de la vida de los individuos y de los grupos, sino que constituye también un instrumento de orientación de la percepción de situaciones y la elaboración de respuestas (Perera, 2005, p. 44). 
En esta línea, al asignar relevancia a la madurez cerebral (y ponerla como requisito previo de la madurez psicosocial), automáticamente se desconocen las vivencias generacionales como herramientas de análisis de la realidad, las cuales conllevan, muchas veces, lecturas alternativas de los fenómenos que, en ocasiones, aparecen como transgresoras y carentes de robustez moral por parte del mundo adulto, por lo tanto peligrosas (de riesgo), porque se alejan de lo que el mundo adulto espera. Así, siguiendo el análisis, como primer factor de riesgo generacional (riesgo en el entendido que no es considerado por la teoría de la madurez), es necesario situar el desconocimiento por parte del mundo adulto de las prácticas y culturas juveniles, muchas de las cuales -según Maffesoli (2003)se presentan totalmente desconectadas del mundo adulto, dando paso a formas diametralmente opuestas de experimentar y vivir la realidad, más lúdicas, estridentes, exacerbadas y con mayores riesgos (que instituyen lo que Maffesoli define como nomadismo). En este sentido, el problema estriba en que los factores de riesgo atribuidos a los mundos juveniles siguen teniendo el sesgo del adultocentrismo, es decir, conductas de riesgo tipificadas con base en los propios criterios del mundo adulto y no a partir de la comprensión que los propios jóvenes les atribuyen. En definitiva, si no se asumen criterios generacionales, la imposición de factores de riesgo seguirá siendo sesgada, adultocentrista y unidimensional.

Íntimamente relacionado con lo anterior, se presenta el segundo factor generacional que dice relación con la reinterpretación de valores que los adolescentes hacen de ciertos preceptos que se asumen fundacionales de una sociedad madura, como la resignificación del dolor, del cuerpo y de la muerte, entre otros. A diferencia de treinta o cuarenta años atrás, donde se asumía que el dolor y la muerte eran preceptos de los cuales era necesario distanciarse, alejarse, porque se presentaban antagónicos al concepto mismo de placer y felicidad. Hoy por hoy, el esquema parece haberse invertido, ya que estos conceptos se asocian de forma directa con lo lúdico y lo hedonista, y, por lo tanto, con lo que se hace necesario experimentar para alcanzar la felicidad.

Los deportes extremos, los tatuajes, los pircing, las perforaciones, entre otros elementos, han llevado a los jóvenes a una familiarización con el dolor (y por ende a soportarlo en mayor cantidad), hecho que ha contribuido a la resignificación del cuerpo, pero también a establecer y reforzar la asociación entre placer y dolor, y entre 
placer y riesgo. Como señala el mismo Maffesoli (2004), muchos jóvenes asumen que lo divertido de la vida está en acercarse lo más posible a la muerte, pero sin alcanzarla. Reconceptualizaciones como esta son las que es necesario tener en mente al momento de comprender la toma de decisiones por parte de los adolescentes. Con esto, entonces, se abre una nueva ventana para comprender la conducta delictual juvenil que se aleja, por un lado, del autocontrol y la madurez intelectual, y se estrecha, por el otro, con la madurez psicosocial, y que apunta a una reconceptualización o, si se quiere, a un cambio de matriz generacional como elemento de análisis de la delincuencia juvenil.

En esta línea, si bien existen esfuerzos por ampliar las variables que expliquen la delincuencia juvenil, como el mapa de factores de riesgo de Borum (2000) que van desde el eje histórico, pasando por el clínico (o de personalidad), hasta los factores contextuales o sociales, me parece necesario avanzar un poco más en este espectro e incluir un cuarto eje de factores de riesgo que podríamos llamar 'generacionales', es decir; que nacen como producto de las propias visiones y reinterpretaciones que los jóvenes (las 'nuevas' generaciones) realizan de los valores y de los preceptos que los adultos asumen como fundacionales de una sociedad equilibrada y normal, y con muchos de los cuales, además, entran en constante conflicto y disenso.

\section{Conclusiones}

Tras revisar los principales supuestos de la teoría del autocontrol y de la madurez (tanto intelectual como psicosocial), es posible concluir que ambas, desde sus propias tribunas, apelan a un determinismo inicial que las sustenta, que, para el caso de la teoría general, se basa en la socialización familiar (rol de los padres en la represión de conductas antisociales), y, para la de la madurez intelectual, en la primacía del desarrollo cerebral por sobre las habilidades emocionales y sociales como herramientas destinadas a resolver conflictos de forma eficiente. En términos concretos, dos propuestas que caminan por veredas opuestas, pero con el mismo bastón.

Esta dinámica dicotómica se rompe gracias a teorías intermedias que buscan consensuar y ampliar la visión del fenómeno, como son las del concepto de madurez psicosocial (Bryan y Casey, 2010), los factores biológicos del autocontrol (Ratchford y Beaver, 2009), 
los factores de riesgo (Borum, 2000), la integradora de Farrington, el modelo de múltiples trayectorias de Loeber y el modelo de desarrollo social de Catalana y Hawkins, entre otros.

De esta manera, cada teoría por sí sola no puede abarcar la complejidad del fenómeno de la delincuencia, pero sí entrega valiosos aportes que deben ser tomados en su justa medida. Así, una explicación de la delincuencia juvenil debe considerar la socialización familiar como un factor de importancia, pero, sobretodo, como punto de partida si se quiere como primer subsistema de análisis (microsistema), que, por cierto, debe considerar las variables biológicas y genéticas de los sujetos, así como sus redes de socialización (escuela, amigos, etc), sus antecedentes históricos y contextuales, al igual que las propias miradas generacionales de los jóvenes surgidas a partir de visiones alternativas (y no necesariamente anormales o patológicas) de la realidad.

\section{Referencias}

Andrews, D. A., Bonta, J. \& Wormith J. S. (2006). The Recent Past and Near Future of Risk and/or Need Assessment. Crime Delinquency, (52), 7-26.

Blonigen, D (2010). Explaining the relationship between age and crime: Contributions from the developmental literature on personality. Clinical Psychology Review, (30), 89-100.

Borum, R. (2000). Assessing Violence risk among Youth. Journal of Clinical Psychology, 56 (10), 1263-1280.

Bourdieu, P. (1990). Sociología y Cultura: La Juventud no es más que una Palabra. México: Grijalbo, Consejo Nacional para la Cultura y Las Artes.

Bryan, C. \& Casey, S. (2010). Psychological Maturity of At-Risk Juveniles, Young Adults and Adults: Implications for the Justice System. Psychiatry, Psychology and Law, 17 (1) 57-69.

Bringas. H. F, Herrero., M, Cuesta y F, Rodríguez. (2006). La conducta antisocial en adolescentes no conflictivos: Adaptación del Inventario de Conductas Antisociales (ICA) Revista Electrónica de Metodología Aplicada, $11(2), 1-10$.

Farrington. D. (2005). Childhood Origins of Antisocial Behavior Clinical Psychology and Psychotherapy. Clin. Psychol. Psychother, (12), 177-190.

Farrington. D. (1986). Age and Crime. Crime and Justice, 7 (M. Torny y N. Morris eds). 
Goffman, E. (1996). Estigma: La Identidad Deteriorada. Argentina: Amorrortu.

Gottfredson, M. R. \& Hirschi, T. (1990). A General Theory of Crime. Standford, Ca: Standford University Press

Gottfredson, M. R. \& Hirschi, T. (1994). The Generality of Deviance. En Traduction Publishers, New Brunswick pp. 1-22.

Herrero, C. (2004). Sobre Introducción a la Criminología de Alfonso Serrano Maillo. Revista Electrónica de Ciencia Penal y Criminología, (6), 4-8, España.

Luengo, A., Gómez-Fraguela, J.A., Garra, A. Romero, E., y Lence, M (1999) La prevención del consumo de drogas y la conducta antisocial en la escuela: análisis y evaluación de un programa. Madrid: PND.

Maffesoli, M. (2004). El Tiempo de las Tribus. México DF.: Editorial Siglo Veintiuno.

Maffesoli, M. (2003). Juventud: El Tiempo de las Tribus y el Sentido Nómada de la Existencia. Revista de Estudios Sobre Juventud, 8 (20), 20-41.

Moscovici, S. (1961). El Psicoanálisis, su Imagen y su Público. Buenos Aires: Ediciones Huemul.

Perera, M. (2005). Sistematización Crítica de la Teoría de las Representaciones Sociales. Tesis Doctoral en Ciencias Psicológicas. Ministerio de Ciencia, Tecnología y medio Ambiente. La Habana: Centro de Investigaciones Psicológicas y Sociológicas.

Ratchford, M. \& Beaver, M. (2009). Neuropsychological déficit, low selfcontrol, and delinquent involvement: Toward a biosocial explanation of delinquency. Criminal Justice and Behavoir, 36 (2), 147-162. International Association for Correctional and Forensic Psychology, EEUU.

Romero, E., Sobral, J. \& Luengo, A. (1999). Personalidad y delincuencia: Entre la biología y la sociedad. Granada: Grupo Editorial Universitaria.

Romero, A. (2014). Análisis de la Conducta de Microtráfico en Niñas y Adolescentes Desde la Perspectiva de la Teoría General del Delito. Última Década, 22 (40), 183-212. Recuperado de http:/ / www.scielo.cl/ scielo.php?pid=S0718-22362014000100009\&script=sci_arttext.

Serrano, A. (2009). Actos de Fuerza, Engaño y Autocontrol. Un test de una teoría general del delito con una muestra pequeña de delincuentes juveniles. Revista Electrónica de Ciencia Penal y Criminología, (11), 1-13. Recuperado de http: / / criminet.ugr.es / recpc/11/ recpc11-13.pdf.

Serrano, A. (2003). Introducción a la Criminología. Madrid: Dykinson. 
Vásquez, C. (2003). Predicción y Prevención de la delincuencia juvenil según las teorías del desarrollo social. Revista de Derecho XIV, 135-158.

Williams, K., Rivera, L. Neighbours \& Reznik, V. (2007). Youth violence prevention comes of age: Research, training and future directions. The Annual Review of Public Health. (28), 195-211. 